\title{
"Una novel·la pornogràfica, per favor!": Escándalo y provocación en la literatura catalana (primera mitad del siglo XX)
}

\author{
Jordi CORNELLÀ-DETRELL \\ School of Modern Languages and Cultures \\ University of Glasgow \\ jordi.cornella@glasgow.ac.uk
}

\begin{abstract}
RESUMEN
Este artículo se propone analizar el papel de la controversia y el escándalo en la configuración del campo literario catalán durante la primera mitad del siglo XX. Los temas principales que se examinarán son el cruce entre la religión y la sexualidad en la literatura modernista, las polémicas causadas por el impacto de las ideas de Freud en los años 20 y 30 y, finalmente, la rigidez moral de los años 40 y 50, que resultó en la marginación de varios autores. Mediante las ideas de Bourdieu y la teoría sociológica sobre el escándalo, este artículo demuestra que la polémica es un elemento consustancial del campo literario que periódicamente ayuda a renovar las técnicas y el estilo literario. Entre las obras analizadas destacan La dama enamorada (Joan Puig i Ferrater), Josafat (Prundenci Bertrana), Els sots feréstecs (Raimon Casellas), Fanny (Carles Soldevila), Aspectes (Salvador Espriu), Una mena d'amor (Cèsar August Jordana), Vida privada (Josep Maria de Sagarra), Laura a la ciutat dels sants (Miquel Llor) y El mar (Blai Bonet).
\end{abstract}

Palabras clave: literatura catalana, franquismo, modernisme, literatura y escándalo, literatura y moralidad, sociología de la literatura.

[Recibido, junio 2014; aprobado, diciembre 2014]

"Una novel·la pornográfica, per favor!": Scandal and provocation in the literatura Catalan (first half of the 20th century)

\begin{abstract}
This article sets out to analyse the role of controversy and scandal in the development of the Catalan literary field during the first half of the twentieth century. The main topics to be explored are the importance of religion and sexuality in the modernista novel, the debates caused by the impact of Freud's ideas in the 1920s and 1930s and, finally, the moral conservatism of the 1940s and 1950s, which led to the ostracism of several authors. Drawing upon Bourdieu's ideas and the sociological theory of scandal, this article shows that controversy is an integral element of the literary field which periodically helps to renovate literary techniques. Among the works examined are La dama enamorada (Joan Puig i Ferrater), Josafat (Prundenci Bertrana), Els sots feréstecs (Raimon Casellas), Fanny (Carles Soldevila), Aspectes (Salvador Espriu), Una mena d'amor (Cèsar August Jordana), Vida privada (Josep Maria de Sagarra), Laura a la ciutat dels sants (Miquel Llor) and El mar (Blai Bonet).
\end{abstract}

Keywords: Catalan literature, Franco's regime, modernisme, literature and controversy, literature and morality, sociology of literature. 
El presente artículo pretende llevar a cabo un análisis de la literatura catalana de la primera mitad del siglo XX desde una perspectiva inédita: el papel de la controversia y el escándalo en la configuración del campo literario catalán. Este enfoque transversal permitirá arrojar nueva luz sobre textos ya conocidos y, también, descubrir los motivos subyacentes tras la marginación de determinados escritores o el rechazo provocado por ciertas obras. Tal como señalan Bourdieu y Haacke, el escándalo, o la amenaza de escándalo, es un instrumento muy poderoso de legitimación que, periódicamente, ayuda a reconfigurar el equilibrio de fuerzas en el campo literario (1994: 84). La lucha que se entabla entre el escritor que desafía los valores establecidos y los defensores del status quo debe entenderse como un juego de posiciones en el que se dirime el reparto de poder y prestigio en la esfera cultural. Como veremos, no parece exagerado afirmar que un campo literario fuerte y dinámico se caracteriza por la erupción cíclica de polémicas que redistribuyen el capital simbólico disponible. Esto implica que, obviamente, un sistema literario sin capacidad para generar debates encontrados ha dejado de funcionar como tal. La razón es simple: para que estalle la polémica, es necesario que exista cierto grado de cooperación entre los críticos indignados, el público - ofendido y fascinado a partes iguales- y una minoría selecta que salga en defensa del acusado. El hecho de que no se cree o no consiga crearse controversia indica que la eficacia de uno de los mecanismos más efectivos para la promoción de los productos artísticos está fallando; esto puede deberse a la falta de interés del público o a la existencia de un grado excesivamente alto de rigidez moral o ideológica.

El concepto de escándalo puede definirse como un fenómeno social que refleja un conflicto entre valores opuestos (Prus y Grills 2003: 4). La creación de una controversia requiere por supuesto cierta complicidad entre las partes implicadas: un artista desafía las convenciones sociales, el crítico inmediatamente salta a la palestra para levantar su dedo acusador y, el público, escandalizado o no, se interesa por la obra objeto de debate. De esta manera, casi todas las partes salen ganando: el agente provocador aumenta su visibilidad y autoridad, y el crítico ofendido se erige como la figura pública necesaria para restablecer el consenso respecto a unos valores que presupone universales e intemporales. Si las nuevas normas se erigen en ganadoras, quienes salen perdiendo son los que no pueden adaptarse a ellas, generalmente escritores ya consagrados incapaces de seguir el camino abierto por las nuevas generaciones, ansiosas de conseguir un espacio propio.

La literatura es una práctica social que, durante los siglos XIX y XX, con frecuencia espoleó el debate en torno a la moralidad y las costumbres. Su amplia difusión y capacidad de reflejar la realidad la convirtieron en un lugar privilegiado para la discusión de temas ético-morales y la experimentación de nuevas formas de entender las relaciones en sociedad. Uno de los papeles fundamentales de la literatura y el arte en general, por lo tanto, ha sido el de someter a examen los principios que rigen la coexistencia civil. El escándalo conllevaba un escrutinio público de las normas vigentes en vistas a reorganizar las normas de convivencia y, estas normas, una vez debatidas ya no pueden permanecer inalteradas, pues el huevo de la serpiente ya ha sido incubado.

Los estudios literarios han tendido a considerar que las interpretaciones de cariz ético son menos sofisticadas que las puramente estéticas (Dromi y Illouz 2011: 3-6). Este prejuicio crítico, sin embargo, no puede esconder que muchas de las obras de ficción más 
populares de -por lo menos- los últimos 150 años han alcanzado su posición privilegiada en el canon no solo por sus logros estéticos intrínsecos, sino por atentar contra el orden moral. ${ }^{1}$ Esto demuestra que el escándalo, lejos de suponer una amenaza para el autor y su obra, si está bien administrado puede convertirse en un mérito que permite acumular una enorme cantidad de capital simbólico $-\mathrm{y}$, a veces, también material. La polémica literaria, por consiguiente, puede utilizarse como un índice del éxito, valor e influencia de determinada obra o autor. El artista que consigue retar las normas establecidas deviene una figura pública cuya obra trasciende los límites de la esfera cultural -aunque, naturalmente, el arte provocador de una generación tiende a convertirse en el lugar común de la siguiente: lo que antaño representó una ruptura, hoy se revela repetitivo y trivial. Tal como indica Bourdieu, todo proceso de consagración acaba por banalizar y devaluar la propuesta original, hecho que enajena al núcleo primigenio de simpatizantes, que tienen que buscar la exclusividad en otros lares (Bourdieu 1996: 254). El escándalo, para resumir, es un componente clave de la vida comunitaria, un acontecimiento público de carácter emocional que periódicamente modifica los valores morales (Jacobsson y Löfmarck 2008: 203).

A principios del siglo XX, la literatura catalana entró en la modernidad gracias a un movimiento, el modernisme, que tuvo en el succès de scandale uno de los mayores instrumentos de revitalización. Los debates en que se vieron inmersos escritores como Caterina Albert, Prudenci Bertrana, Joan Puig i Ferrater o Santiago Rusiñol reforzaron su legitimidad como artistas, hasta el punto que, más de cien años después de la publicación de sus obras más rompedoras, aún siguen percibiéndose como textos que socavaron los cimientos de la sociedad de la época. Hay que subrayar que ha sido el boca-oreja, el comentario de lector a lector, lo que ha afianzado la reputación de estas obras, tanto o más que los estudios académicos que les han sido dedicadas.

Por un lado, muchos de los autores modernistas desafiaron conscientemente el orden moral y gusto burgués, parapetado tras la institución de los juegos florales; por otro, estos mismos escritores con frecuencia convirtieron el concepto de escándalo en el motor principal de sus textos. En las obras dramáticas de Joan Puig i Ferreter este enfoque dual se observa claramente: La dama alegre (1904), que los empresarios del teatro Romea rechazaron por inmoral, tiene de protagonista a una mujer, Marta, que "ha donat escàndol només per a fer crèixer dins d'aquesta gent el corc de l'enveja. M'ha agradat veure-les, aquestes dones prudentes i honrades, amb l'enveja als ulls, sentint ganes de ser com jo" (2001: 72). Marta, que se pasa todo el primer acto coqueteando con varios hombres, considera que la religión "mata tot goig humà" (53) y se define como "sola, lliure, alegre, disfrutant eternament de la meva llibertat" (72). La actitud de la dama alegre, muy poco respetuosa hacia su marido, indigna a su hijo, que le acusa de prostituirse. Puig i Ferrater despliega una calculada ambigüedad: en el primer acto, la audiencia no puede sino admirar el entusiasmo desbordado y ansia de libertad de la protagonista, enfrentada al fanatismo religioso de su entorno; en el tercero, sin embargo, se descubre que es una mujer manipuladora, mucho menos inocente de lo que aparenta. El último acto revela que el hijo

\footnotetext{
${ }^{1}$ Se ha elegido esta fecha porque el cuadro de Édouard Manet Le Déjeuner sur l'herbe (1862-1863) acaba de cumplir 150 años. Este lienzo provocó el primer gran escándalo del arte contemporáneo y por lo tanto es el primer ejemplo moderno del fenómeno tratado aquí, que los franceses denominan succès de scandale.
} 
de Marta, a quien ella siempre ha despreciado, sabe perfectamente que es fruto de una relación ilegítima con un criado, lo que justifica su actitud agresiva. Como resultado, el espectador se convierte en testigo de un drama que le apremia a tomar partido entre la independencia sin ataduras de la dama o la sujeción a los convencionalismos sociales. El valor de la obra radica en que no hay una elección clara: tanto la independencia como el sometimiento a las normas provoca daños colaterales.

En Aigües encantades (1907), que incluye desafiantes observaciones anticlericales, los propios personajes tienen que hacer frente al revuelo que provocan sus ideas avanzadas. La pieza relata el enfrentamiento entre la masa conservadora y tradicionalista de un pueblo de montaña y un joven con conocimientos de ingeniería que pretende canalizar las aguas de un estanque donde supuestamente tuvo lugar un milagro. La osadía del joven ofende profundamente a los lugareños, que perciben sus ideas como un ataque a su modo de vida tradicional. La amiga del joven, además, horroriza al párroco y a su familia atreviéndose a besarlo en público. El escándalo, por consiguiente, incumbe tanto el objetivo del autor respecto a la recepción del texto como el mismo tema de la obra; esta es una característica general de un movimiento que, enfrentado a una sociedad a la que considera retrograda y hostil, dramatiza la lucha entre los instintos y la cultura, la represión y la autorrealización, la religión y el racionalismo.

Los héroes modernistas de Puig i Ferrater avanzan decididos por la senda del autoconocimiento, pero este es un camino traumático que choca con los prejuicios sociales y la mentalidad obtusa de la masa. Aigües encantades, como muchas otras de esta tendencia, se distancia de la visión arcádica y folclórica del campo que perpetuaba el tradicionalismo conservador mediante la representación de un ámbito rural atrasado, brutal y trágico, un espacio hostil y agreste que representa la antítesis de la modernidad (Marfany 1975: 29). Los intentos de transformar este espacio a través de la tecnología y la razón fracasan en Aigües encantades y, como veremos, la regeneración mediante la fe es derrotada en Els sots feréstecs de Raimon Casellas (1901) y Solitud (1905) de Caterina Albert.

El modernisme ansiaba renovar una cultura percibida como falsa, provinciana y atrasada (Marfany 1975: 17); al mismo tiempo, pretendía dignificar y profesionalizar la vocación del artista. Sus integrantes conciben el arte como una actividad superior, digna y exigente, y por ello impulsan una rebelión contra la burguesía, atrincherada en unos juegos florales que ven como poco más que un pasatiempo caduco que promueve una literatura de cartón-piedra. Entre los escritores modernistas que reaccionaron contra los presupuestos ideológicos y estéticos de los jocfloralistes cabe destacar Santiago Rusiñol, que en la farsa Els Jocs Florals de Canprosa (1902) ridiculizó sin piedad todos los aspectos de la festa, hasta el punto que fue tachada de anticatalana por una parte de la sociedad barcelonesa (Casacuberta 1997: 321-327). El mismo Rusiñol, al año siguiente, consiguió ser acusado de antiespañol gracias a L'hèroe (1903), lo que demuestra su versatilidad como polemista. Esta hiriente sátira sobre las consecuencias de la Guerra de Cuba indignó al ejército y fue suspendida por las autoridades inmediatamente después de su estreno en el Teatro Romea.

Los juegos florales, con su gusto por el medioevo, el folklore, la ingenuidad sentimental y el academicismo artificioso, fueron blanco fácil de los modernistes, que los acusaron de defender un orden moral, político y religioso alejado de Europa y de las necesidades de la sociedad catalana. Los juegos florales tenían el monopolio de la expresión literaria culta en lengua catalana (Casacuberta 2010: 76), y por consiguiente era el estamento que los modernistas tenían que demoler para instituir una nueva dinámica en el campo literario. A 
tal efecto, desarrollarán una nueva escala de valores afianzados a base de escándalos. El escritor modernista se siente marginado por un entorno que todavía no entiende su concepción moderna del arte, y para reivindicar su estatus y reformar el campo cultural adopta una actitud rebelde e iconoclasta.

Este proceder queda ya asentado en la obra seminal del movimiento, Els sots feréstecs (véase Castellanos 1992, 2: 238-277). Casellas relata la lucha entre un bienintencionado párroco recién llegado a un remoto pueblo de montaña y Rodasoques, una prostituta entrada en años que, con sus dudosos encantos, consigue subyugar la voluntad de los hombres de la región. Inicialmente, mosén Llàtzer intenta inculcar el amor a dios a los feligreses, pero su fracaso lo lleva a tratar de atemorizarlos con la amenaza de la cólera divina. Ambas estrategias fallan ante el hechizo de Rodasoques, y mosén Llàtzer no consigue la paz ni en su lecho de muerte. En el último capítulo, que presenta tintes sobrenaturales, el párroco sufre un ataque que lo deja paralizado y los lugareños le organizan un funeral en vida; mosén Llàtzer, consciente pero inmovilizado, tiene que presenciar como la prostituta hace gestos lascivos ante su cuerpo inerte. Muchas obras modernistas tienen en común un anticlericalismo más o menos acusado; ésta parece ser una característica intrínseca del movimiento que pocas veces se ha tenido en cuenta. Si bien el cura de Els sots feréstecs es un personaje connotado positivamente, el hecho que sea humillado por una meretriz que, además, ejerce en una ermita, indica que el texto acepta lecturas múltiples. Ciertamente el lector puede empatizar con el sacerdote, pero su derrota es tan rotunda y humillante que el texto ofrece muy pocas esperanzas respecto a la capacidad transformadora de la fe.

El intelectual modernista, que pertenece a la primera generación que reivindica poder vivir de y para el arte, idealiza - sin duda porque se ve reflejado en él- el ser marginado. Sus ideales del artista modernista, en efecto, chocan contra la apatía general, y la única salida digna a una vocación incomprendida es poner énfasis en la diferencia, transformar el arte en una misión sagrada y buscar el enfrentamiento para, por lo menos, sacudir las conciencias indiferentes. Obviamente, un ámbito donde la controversia estaba asegurada era el de la sexualidad, ya que el cruce entre la experiencia erótica y la moral pública es uno de los puntos más sensibles del encaje del individuo en la sociedad. Conscientes de ello, los escritores modernistas emplazan el erotismo, presentado como una fuerza instintiva descontrolada y destructora contra la cual no se puede luchar, en un lugar central de su ideario estético (Castellanos 1989: 29-30). Incluyen, además, el sentimiento religioso en la ecuación. Puesto que el escritor modernista se ve como un sacerdote del arte, no sorprende que se apropie de la imaginería católica, pero con un transgresor giro erótico que enfatiza el goce por lo ilícito. Tal como afirma Yates, el misterio de la religión y el esplendor de sus ritos constituyen un decorado perfecto para incrementar el placer estético y carnal (1975: 61).

Esta sexualidad, que a causa de las convenciones sociales no ha podido desarrollarse de forma natural, es con frecuencia perversa y desesperada. Como resultado de la tensión no resuelta, las experiencias espirituales adquieren visos sacrílegos: en Els sots feréstecs, la victoria de Rodasoques -que ejerce el lenocinio en una ermita- lleva el mosén a la muerte. En Josafat, el espacio de la seducción, la catedral, será el lugar donde el protagonista asesine a su amante y, en Solitud, la comunión de la protagonista con la naturaleza llega a su fin cuando es violada en la ermita de Sant Ponç. Desarrollar la pugna de los protagonistas en un entorno sacro, claro está, agudiza el contraste entre la sexualidad instintiva y las fuerzas de la represión, proporcionando un placer más refinado y añadiendo más elementos para la 
polémica. La ignorancia de la propia identidad, por otra parte, deriva en perversiones, violencia y masoquismo, como observó Castellanos (2001: 37-8; véase también Olcina 2012: 54). Camí de llum (1909) de Miquel de Palol, por ejemplo, insinúa una relación incestuosa entre padre e hija, y Josafat (1906) de Prudenci Bertrana aúna el misticismo con el crimen y un amago de necrofilia. Una de las obras más sórdidas es sin duda L'adolescent (1909) de Alfons Maseras, una narración sobre la caída de Babilonia tan decadentista que, a ojos contemporáneos, raya lo paródico. Los amores entre la madura Ninniur y su hijastro adolescente Nekarim, que transcurren en un ambiente de lujuria desatada, adquieren un notable aire malsano, sobre todo cuando ella, después de haberlo estrangulado, lo besa y acaricia apasionadamente.

Respecto a Solitud de Caterina Albert, poco cabe añadir a la iluminadora lectura de Bartrina, que examina los aspectos sexuales y de género de la novela, con frecuencia relegados en pos de una lectura que atenúa su componente erótico, elemento aún más problemático por el hecho que la protagonista es una mujer. Cabe recordar que la primera obra de Albert, La infanticida, premiado en los Jocs Florals de Olot (1898), también provocó un vendaval. En este monólogo, la protagonista representa tan poco para su padre y hermanos que, antes de su infanticidio, ni se habían dado cuenta de que estaba embarazada (Bartrina 1997: 81). En un ejemplo de realidad imitando la ficción, el jurado tampoco advirtió de entrada que el autor de la pieza era en realidad una autora. Albert, traumatizada como resultado del escándalo, decidió adoptar un seudónimo masculino, hecho que muestra que, debido a la misoginia y el androcentrismo, la polémica literaria es mucho menos tolerable cuando la protagoniza una mujer.

Josafat de Prudenci Bertrana es una novela profundamente sensual, tanto en el contenido como en la forma. La trama, que se centra en los amores ilícitos de un campanero y una prostituta en la catedral del Girona, no deja lugar a dudas respecto a las intenciones del autor. El protagonista, profundamente religioso, intenta reprimir sus impulsos, pero a pesar de sus esfuerzos no puede resistirse a los encantos de Fineta. El fanatismo religioso del campanero le impide convertirse en un hombre pleno (Farrés 1994: 30), y detrás de su defensa de la integridad moral se esconde un ser incapaz de controlar sus instintos (Castellanos 2001: 27). La sociedad, por lo tanto, impone unos códigos de conducta que lleva a los individuos a enfrentarse a su propia naturaleza: "en ésser vençut per l'instint, per la pròpia necessitat biològica -el sexe-, l'home que no pot suportar el pes de tanta contradicció, és víctima d'ell mateix i de la seva violencia" (Nadal 1995: 12). En esta lucha, los instintos arrollan al individuo porque no han sido integrados en el yo, sino simplemente reprimidos. Las normas de conducta impuestas, sin embargo, no son lo suficientemente poderosas como para prevalecer y los impulsos terminan aflorando, pero de forma violenta y descontrolada.

Cabe destacar que el tema de Josafat, en sí muy sugerente, es evocado a través de una profunda sexualización del lenguaje. En uno de los pasajes más irreverentes, por ejemplo, Fineta se restriega el cuerpo con la cuerda de una campana (57), y el hecho que se indique en repetidas ocasiones que el campanero toca el flautín no es nada inocente ("la castedat el fa sofrir, tragué el seu flabiol"; 2001: 34). Gabriel Ferrater quizá se equivocaba de novela al tachar Solitud de alucinación erótica (Calderer 1995: 58); este honor corresponde a Josafat desde la primera frase del texto: "La gran pila, amb la seva tapa clavetejada, els seus baixos relleus primorosos $\mathrm{i}$ el seu contorn elegant, despareix a l'ombra espessa, impregnada de l'especial efluvi que només es desprèn de l'aigua beneita." (25)

Josafat se convirtió en una obra controvertida desde el principio, ya que no le fue 
concedida el premio de la Festa de la Bellesa de Palafrugell (1905) porque el jurado, a pesar de alabar sus características estéticas, la consideró demasiado atrevida (Granell 2006: 15). El propio autor, lejos de amilanarse, azuzó el debate sugiriendo que la trama estaba basada en hechos reales y el protagonista era en realidad un sacerdote (Pla 2012: 102-103). La estrategia funcionó, porque el libro tuvo que reeditarse al cabo de pocos meses. En los círculos más conservadores de Girona, la novela fue considerada una afrenta intolerable, tal como muestran algunas reseñas: "Josafat es la producción más asquerosamente carnal que he visto en siglos. Bertrana en este libro ha puesto las groserías más procaces para dar cuerpo a la carnalidad más abominable" (Anónimo 1910: 11). El autor se defendió con una declaración de principios que resume a la perfección los postulados modernistas respecto al arte y la moralidad: "Yo busco la belleza á todo trance y cuando la hallo, esté donde esté, sea como sea, siento una fuerza interior que me obliga a producir la obra" (1910: 11). La controversia forzó a Bertrana a autoexiliarse en Barcelona, pero no arruinó su carrera; bien al contrario, ya que esta es la obra mejor conocida $-\mathrm{y}$, de hecho, la única que aún se lee- de su irregular trayectoria. En todo caso, tal como descubrió Granell hubo muchos intelectuales, como Lluís Via y Carme Karr (2002: 252), que dieron apoyo al autor. Josafat, sin embargo, no ha pasado a la historia por estas reseñas positivas, que yacían olvidadas hasta que la estudiosa las rescató, sino por las negativas, que multiplicaron el prestigio de la obra en el mercado literario. No resulta exagerado afirmar que Josafat está en el canon gracias a aquellos agrios comentarios de principios del siglo $\mathrm{XX}$; sin ellos, quizá estaría tan desatendida como el resto de la producción del autor. No puede negarse su valor artístico intrínseco pero, indudablemente, éste ha sido determinado por factores extraliterarios que han sido clave en la recepción posterior del texto. Ninguna obra literaria es inherentemente polémica y, tal como afirma Howells, las disputas en torno al arte no son nunca un simple conflicto entre opciones estéticas (2012: 19). Su alcance y significado, por lo tanto, tiene que localizarse en la esfera social y política.

Exageraba Yates cuando afirmó que en Nàufrags (1907) de Bertrana el "misticisme eròtic penetra tota la novela" (1975), porque si bien en esta obra aparecen temas ya tratados en Josafat, están bastante más constreñidos por la moralidad de la época. El tema de Nàufrags -que, como no, levantó polvareda- no es infrecuente en las dos primeras décadas del siglo XX: un seminarista se debate torturadamente entre su vocación sacerdotal y sus inclinaciones libidinosas. All i salobre (1929) de Josep Maria de Sagarra, que "mereció un éxito de escándalo, desproporcionado con las crudezas accidentales de un libro que es un poema del más negro pesimismo" (Tasis 1937: 52), trata el mismo tema, pero de manera harto más explícita. Lo que en Nàufrags se envuelve en una nebulosa capa de reflexiones místicas, en All $i$ salobre adopta un realismo más crudo, particularmente cuando el seminarista relaja sus tensiones con la práctica del onanismo ("va resoldre la tempesta de la sang amb una vulgaríssima maniobra"; 1929: 39) y cuando visita un lupanar en Girona. Este capítulo, que describe el barrio rojo de la ciudad, se había publicado independientemente en el semanario L'Opinió en marzo de 1928, y las protestas alcanzaron tal magnitud que en la novela fue censurado. Veamos una de las frases expurgadas, que no aparece ni en las ediciones más recientes:

\footnotetext{
De les noies que passen pel carrer n'hi ha que ensenyen uns ulls escurats pel desig, van penjades del braç de nuvi i la boca els crema com si els haguessin pintat les genives amb salfumant. N'hi ha d'altres que sospiren, es pensen que l'aire és tot ple de sucre, altres que s'amaguen el pit amb un vel i altres que sembla que duen una bombeta elèctrica en el baix ventre perquè tothom s'adoni que són
} 
Los motivos del agravio aún están vivos en la memoria popular: en diciembre de 2010 un periodista del Diari de Girona recomendó la novela en uno de sus artículos (Vilamitjana 2009: 26) y, al cabo de unos días, se publicaba una carta al director protestando por la sugerencia (Costa i Torró 2010: 4). Según la lectora, como respuesta a las calumnias de Sagarra un grupo de gerundenses intentó pegarle una paliza, pero la cosa no fue a mayores y "Les noies gironines, com vertaderes descendents de les 'Heroïnes de Santa Bàrbara' defensaren la seva dignitat".

Si el modernisme destaca por enfrentarse a los valores circundantes, el noucentisme que lo siguió se caracteriza por todo lo contrario, ya que pretendía inaugurar, en palabras de Eugeni d'Ors, "una era de fresca moralitat, de reconquerida salut, en els cors i en les ments..." (2005 [1913]: 553). Este movimiento, al servicio de las aspiraciones de la Lliga Regionalista, afianzó su dominio en la esfera literaria tras el triunfo electoral de 1913. La lógica del campo cultural lleva a periódicas luchas generacionales por la legitimidad artística, y el noucentisme impuso sus normas gracias a la interacción con otro campo, el del poder, al cual los modernistas no tenían acceso. Gracias a este apoyo, el noucentisme impuso sus criterios y desacreditó el movimiento precedente con inusitada rapidez. Como indica Bourdieu, los cambios de tendencia siempre son el resultado de un doble movimiento: el interno, que sólo afecta las reglas del campo literario, y el externo, que incumbe crisis políticas o cambios en las relaciones de poder (1996: 254). El noucentisme exigía el sometimiento de los intelectuales a un programa estético y político de inspiración católica y conservadora (véase Panyella 2010). No es extraño, por lo tanto, que rehuyese toda controversia, se avergonzara del modernisme -tachado de primitivo, brutal y caótico- y se refugiara en valores de orden como la civilidad y el clasicismo. Como es bien sabido, el resultado de esta aversión hacia cualquier atisbo de conflictividad condujo a la marginación de la novela, género que se percibía como poco apto para reflejar la realidad catalana, demasiado desagradable para el refinado gusto noucentista. Los escritores noucentistes, para alcanzar sus ideales de perfección y totalidad, se volcaron en la lírica, pero a mediados de los años 20 se hizo evidente que era esencial volver a conectar con el público. Como resultado, el género novelístico resurgió, y con él la polémica, uno de sus elementos consubstanciales.

En un contexto donde la prioridad era ampliar la difusión de la literatura en catalán y sentar las bases de un campo cultural completo y autónomo, escritores como Carles Soldevila, Josep Maria de Sagarra, Salvador Espriu, Miquel Llor y Cèsar August Jordana se lanzaron a romper tabúes para atraer la atención del público. Los años 20 y 30 son un periodo todavía poco estudiado (véase Pla 2010a y Real 2006: 69-94) durante el cual avanza el proceso de alfabetización, los libros se abaratan considerablemente, las editoriales se profesionalizan y aparecen nuevos periódicos y revistas que alcanzan una mayor tirada, hecho que hace incrementar la audiencia. A finales de la década de los 20, los escritores renuevan las convenciones literarias adoptando técnicas en boga en toda Europa como el monólogo interior y abrazando las ideas de Freud, que convierten el erotismo en motor del comportamiento humano (Angelats 993: 65). Buena parte de las controversias de esta época, alimentadas por la prensa, se produjeron porque el psicologismo estaba desplazando la fe como explicación de la conducta individual (Rose 1998: 69), lo que causó tensiones ente los sectores laicos o moderados y los más religiosos. El nuevo paradigma ahondaba en los 
rasgos psicológicos del individuo, que estaban en proceso de desplazar los valores metafísicos de la religión. No es casualidad que el protagonista de El doctor Rip sea un galeno, que en Fanny se hable constantemente de la medicina (Cornellà-Detrell 2012) y que en Tàntal, Vida privada o Una mena d'amor la atención a los temas religiosos sea mínima o inexistente. Para los personajes de estas novelas, es evidente que la salud del cuerpo y la mente es mucho más importante que la salvación del alma, y por esto necesitan a un médico y no un cura, personaje clave en la novela modernista que tiene un papel cada vez más secundario a medida que nos acercamos a la guerra civil.

En épocas de cambio del paradigma cultural, la literatura cumple una doble función: por un lado, refleja las actitudes cambiantes de la sociedad; por otro, ella misma es agente activo de esta mudanza. Las obras citadas ponen énfasis en los estados mentales y la sexualidad de los personajes para quitarles la máscara y presentarlos tal como son, sin las barreras protectoras que interponen la religión, los convencionalismos, la moralidad y la educación. Este proceso inquietó sobremanera a críticos católicos como Manuel de Montoliu, articulista prolijo y gran adalid de la moralidad en los años 30. Desde la perspectiva contemporánea, sería fácil considerar sus recensiones como simples excentricidades de un puritano acérrimo, pero lo cierto es que sus dictámenes en La Veu de Catalunya, recogidos posteriormente en los cuatro volúmenes de su Breviari crític (1926-1933), representaban a un amplio sector de la sociedad catalana. La ironía es que este crítico, al que Fuster calificó de «monja momificada» (Fuster, 2010: 166), ha conseguido hacerse un hueco en la historia literaria no por la brillantez de sus juicios, sino por su intransigencia y mojigatería.

Un buen ejemplo de ello es su lectura de Tàntal (1928) de Miquel Llor, una obra muy novedosa que todavía hoy es difícil situar en el panorama literario de los años 20, cosa que explica su pobre recepción crítica (véase, sin embargo, Arnau 1987: 19-31). Tàntal es un texto discursivo con apenas trama que, según Montoliu, raya la pornografía (1928), pero no por contener pasajes sexualmente explícitos, que no los tiene, sino simplemente porque Llor se inspiró en las teorías de Freud para trazar la personalidad del protagonista. Éste es un individuo apagado y abúlico, un ser inane y contradictorio que reacciona de manera imprevisible. El énfasis casi exclusivo en su torturada psicología debió ser poco entendido, y quizá por esto en su siguiente novela Llor se decantó por una trama de corte más decimonónico - que, sin embargo, incluye pinceladas freudianas. En el caso de Laura a la ciutat dels sants (1931), que se convirtió en un best-seller, la controversia se produjo a causa de la identificación entre la ciudad ficcional donde transcurre el argumento -Comarquinaly Vic. Llor, lejos de amedrentarse, en una entrevista de Mercè Rodoreda en Clarisme se burló de la ciudad:

Pocs llibres hi entren, tot just tres o quatre exemplars de cada novel·la. De la Laura n'hi entraren quatre-cents; això és una prova de la curiositat que desvetllà, i a la biblioteca de la ciutat -que sense jo anomenar es reconegué- a les noies joves se'ls privà la lectura del meu llibre per creure-la massa avançada; i és que en el fons, encara que s'hagi modernitzat, encara que tingui electricitat, $i$ altres novetats d'aquestes, continua essent el que fou en temps de la meva àvia. Una ciutat de falsos sants, embolcallada de boira. (1933: 2)

Llor ofrece un retrato devastador de una sociedad provinciana y ultraconservadora aprisionada por la tradición donde, sin embargo, los personajes no pueden evitar que afloren sus deseos reprimidos (Gadea i Gambús 1994: 99). Laura es una barcelonesa cosmopolita y libre que se casa con el heredero Tomàs y se va a vivir a Comarquinal, donde asistirá a un 
desfile de mezquindades y sexualidades frustradas: la brutalidad de su marido, que abusa de ella; la terrible represión de su cuñada, retratada a través de las reacciones de su subconsciente; la castradora sublimación a través del arte del cura, y el acoso de Llibori, uno de los bastiones morales de la ciudad. El impacto de esta novela fue tal que Vic ha adquirido el apodo de "ciutat dels sants", certificando este hecho que, tal como indican Howells, Ritivoi y Schachter (2012: 1), las controversias entorno al arte se caracterizan por transcender el campo estrictamente cultural.

En la deliciosa Fanny (1929), Carles Soldevila narra la vida de una joven de buena familia que, como resultado de la ruina económica de su padre, termina bailando en una revista de El Paral·lel barcelonés, actividad que para la gente biempensante de la época equivalía a prostituirse. Lo más provocador de este texto es que Fanny no solo consigue integrarse perfectamente bien en su nuevo ambiente, sino que, por ende, lo prefiere a la hipocresía de su clase social. La protagonista, que en su nueva vida descubre el valor de una libertad que hasta entonces le había sido negada, rechaza los valores encorsetados de la parte alta de Barcelona y desarrolla una nueva identidad que le permite trabajar, ser independiente y, como último tabú, tener relaciones sexuales por placer. Casacuberta (1995: 39) argumenta que esta obra no es tan rompedora como parece, ya que al fin y al cabo la protagonista es una burguesa caída en desgracia y la acción transcurre en el Paral·lel, el único ámbito en la literatura del primer tercio de siglo donde era "aceptable" que una mujer tuviera relaciones sexuales fuera del matrimonio. Era aceptable, claro está, porque se presuponía que cualquier fémina integrada en este ambiente se había perdido sin remisión. El argumento de Casacuberta es sin duda válido, pero no tiene en cuenta que el solo hecho de mostrar una conducta heterodoxa, esté enmarcada o no en un contexto que la imbuya de moralidad, ya otorga cierta legitimidad a la circunstancia descrita, puesto que da una visibilidad al tabú de la que antes carecía. Mostrar el tabú, aunque sea para condenarlo veladamente, es un acto de rebeldía en sí que incita al debate público en torno a la aceptabilidad - o no- del hecho narrado. Este es un recurso muy utilizado por los escritores de la época; Sagarra, por ejemplo, quizá era homófobo o expresaba prejuicios de clase (Gustà 1981: 45), pero el hecho de incorporar personajes homosexuales en una novela de alcance popular como Vida privada provoca que, por primera vez, este sea un tema tratado abiertamente en la literatura catalana.

El peligro de enjuiciar mostrando no pasó inadvertido a los críticos, que en sus reseñas dejaron de lado las supuestas interpretaciones de tono moralizante de las obras anteriores y se centraron en su explicitud. Según Montoliu, por ejemplo, Fanny batió "el record de l'absurditat moral, psicològica i estètica" porque intentaba "invertir certa valors eterns en el món moral” (1930: 259); en opinión de Capdevila, que comparte el mismo punto de vista, la novela era recusable porque estimulaba la curiosidad del lector por razones extraliterarias (1929). La osadía de Soldevila reside en atreverse a reflejar los cambios que estaba experimentando el papel de la mujer en la sociedad y, también, en hablar de la sífilis, ya que una amiga de la protagonista, envidiosa de su éxito, divulga el rumor que tiene la enfermedad de "les tres i". La primera edición de Fanny no tardó en agotarse gracias al estruendo (en 1935 ya se habían vendido 10.000 ejemplares; Casacuberta 1995: 79), y la segunda incluye un prólogo donde el autor denunciaba el exceso de puritanismo: "Un sector de la crítica més inclinat a l'exercici de la censura eclesiàstica que al de la censura literària, ha titllat d'immoral la meva novel·la. Hi ha vist una apologia del llibertinatge i una exaltació del paganisme." (1930) Soldevila acepta que su obra es quizás amoral, pero que de ninguna 
manera era inmoral.

En 1931 Cèsar August Jordana publica Una mena d'amor, la primera novela erótica catalana moderna. El escritor, que en sus obras de los años 30 hizo gala de una gran ironía y voluntad desmitificadora, era partidario de una literatura de alcance popular y gustos mayoritarios (Grau 1995: 10). A tenor de lo que escribe Mercè Rodoreda en Aloma, con Una mena d'amor consiguió su propósito: la protagonista compra el libro de Jordana en un quiosco para leerlo a escondidas de su familia. Jordana siempre negó la influencia de D.H. Lawrence (Iribarren 2011: 11-13), aunque un interesante artículo de Campillo parece sugerir lo contrario (1977). En cualquier caso, la novela se centra en el arrebato pasional que sufre un joven de mentalidad abierta ("ell no havia fet mai professió de viure segons les convencions"; 1995: 101) dispuesto a todo -incluso a robar a su padrastro- para satisfacer su libido. Una vez se ha acostado con el objeto de su deseo, evento que se describe en el capítulo cuarto, pierde rápidamente el interés en la muchacha. Ramona, sin embargo, queda prendada de él, pero su falta de educación le impide comprender las aspiraciones artísticas de su amante, que escribe poesía. Como Fanny, Una mena d'amor transcurre en el Paralelo, único espacio de la ciudad donde era posible abordar el tema del sexo sin causar demasiado- escándalo (Castellanos 1989: 119). Como bien indica Campillo (1977: 106), la diferencia principal entre las dos novelas es que mientras en Fanny la protagonista entabla una lucha con sus prejuicios morales, en Una mena d'amor el único conflicto gira en torno al dinero que el protagonista necesita para poseer la meretriz y su remordimiento por haberlo robado. Las mujeres que terminan en el Paralelo, lugar de perdición y desenfreno por antonomasia en la literatura catalana del siglo XX, quedan estigmatizadas socialmente y ya no pueden redimirse, lo que explica que los hombres de ambas novelas puedan dar rienda suelta a su concupiscencia sin reparo alguno. Éste, claro está, es un lugar común de visos misóginos utilizado para condonar el comportamiento licencioso del sexo masculino, al que le es permitido desahogarse con unas mujeres que, al fin y al cabo, ya han perdido su virtud. Una mena d'amor participa de esta ideología, pero por lo menos no presenta ninguna connotación moralizante: el acto central es una aventura banal e intrascendente que en nada modifica la vida de los protagonistas (Campillo 1977: 108).

No obstante la controversia causada por las novelas precedentes, la actitud de Aloma demuestra que había un público dispuesto a consumir obras en conflicto con los valores circundantes. Y, a pesar de las invectivas de Montoliu $-\mathrm{y}$ las opiniones más templadas Guansé o Jaume Vidal Alcover (véase Grau 1995: 17-18)-, tampoco faltaron críticos que las defendieron. Rossend Llates, por ejemplo, denunció que la única novela inmoral era la blanca o sentimental, que "és la pornografia servida en blanques, elegants i menudes píndoles homeopàtiques. / És el vici dels inconscients, dels imbècils i de les millors famílies." (1929: 4). Un anónimo A.F. -que según Castellanos (1982: 118) esconde el mismo Llates- defendió Fanny en un artículo titulado "Una novel·la pornogràfica, per favor!" en el que pedía la publicación de novelas eróticas para que los lectores católicos supiesen lo que eran (1930: 4; Casacuberta aduce que el autor fue Just Cabot, 1995: 38). Agustí Esclasans, por su parte, indicó que al público había que darle de todo, “del cim de la moralitat al cim de la inmoralitat" (1925: 167), ya que si no tenía acceso a un amplio repertorio de géneros su interés se dirigiría hacia las obras en castellano. Según Guansé, entre las clases pudientes existía la creencia que la novela era peligrosa para la juventud, pero a su parecer la novela sentimental era aún "més perniciosa que aquella que s'adreça directament als sentits" (1931: 4). 
Vida privada (1929) de Josep Maria de Sagarra, que vendió 5.000 ejemplares en menos de doce meses (Pla 2007: 396), fue una de las novelas más leídas y discutidas en la década de los 30 . El mismo año de publicarse ganó el premio Crexells que, como todo galardón que ansíe llegar al público no especializado, fue salpicado por todo tipo de polémicas (Casacuberta 1995). Montoliu, en fin, describió Vida privada como una "depriment simfonia erótica" aquejada de "freudisme mal digerit" (1933: 7). Guansé, por su parte, lamentó que Sagarra no describiese "sino la part prostibularia, la part de degeneració pasional. La resta es veu ofegada sota aquesta pintura grassa i excessiva" (La Publicitat, 1932, cit. Pla 2007: 397). El autor retrata la corrupción y decadencia de la vieja aristocracia catalana, que de día frecuenta el elegante distrito de L'Eixample y de noche da rienda suelta a sus vicios en El Paral·lel. El choque entre los Lloberola, miembros de una nobleza en vías de extinción, y la nueva burguesía industrial, se examina a través del comportamiento libertino de la primera, arruinada tanto económica como moralmente.

Gustà considera que Sagarra utiliza el sexo para reforzar los prejuicios morales y de clase del narrador (1981: 45). Si bien las supuestas aberraciones se describen con detalle, no parece haber nada de liberador en ellas, ya que solo sirven para censurar a quienes las practican. A pesar de ello, y como en el caso de Fanny, si la obra fue criticada es por su peligrosa ambigüedad: ciertamente reprueba el comportamiento de algunos personajes, pero lo hace aludiendo explícitamente a sus prácticas hetero y homosexuales. La actitud del narrador, por lo tanto, es más ambigua de lo que apunta Gustà, y cabe preguntarse si Sagarra ahondó en la descripción de prácticas tabú para desacreditar a los Lloberola, o bien si eligió desautorizar a los personajes a través de su comportamiento sexual porque esta era la única manera que permitía al narrador recrearse en su inmoralidad. Que esta posibilidad no es gratuita lo prueba el hecho que el editor y el autor, para favorecer las ventas, alimentaron el rumor según el cual Vida privada era un roman à clef que retrataba individuos reales, extremo que ningún crítico ha confirmado. Sea como fuere, el éxito de la novela fue indiscutible, pero a largo plazo acarreó serios problemas a Sagarra, ya que durante la posguerra la resistencia cultural marginó al autor porque en los felices 20 y principios de los 30 se había regodeado en la obscenidad (Pla 2010b: 606).

Uno de los casos más interesantes y paradójicamente desconocidos es el de Salvador Espriu, que en los años 30 -dato que se olvida con frecuencia- era considerado un narrador y no un poeta. Su primera obra en catalán, con la que claramente pretendió epatar a los lectores, versa sobre un médico descreído que, aquejado de cáncer, decide suicidarse. La recepción de El doctor Rip (1931) fue más tibia de lo esperado por el joven Espriu, pero el autor persistió y su siguiente novela, Laia (1932), ya llamó la atención de Montoliu i Tasis, que la consideraron, respectivamente, una "obra moralment malsana" y "una mica repel·lent" (1932, cit. Espriu 1996: 32). En los años 40 Espriu reescribió buena parte de su obra narrativa, y la comparación entre las versiones de Laia de la década de los 30 y las de postguerra muestra con diáfana claridad hasta qué punto el trauma del conflicto alteró el campo cultural. Espriu se embarcó en un ambicioso proyecto de revisión de sus textos que, obviamente, tenía por objeto mejorarlos estilísticamente, pero que también pretendía adecentarlos desde un punto de vista moral. La Laia de 1932 es una obra anticlerical, violenta y explícita respecto a la sexualidad de los personajes, características que desaparecen en la versión de 1952 (para un análisis pormenorizado, véase Cornellà-Detrell 2011). Unos pocos ejemplos de las narraciones de Aspectes (1934) bastarán para demostrar este argumento: en el relato La rierada, la frase "No tens vegonya, Werner, mira que lligar- 
te porcament... així... com una bèstia... per inèrcia! I per això t'ha servit la murrieria de tanta trotada? Vagabund afamat!" (Espriu 1998: 32) se transforma en 1952 en un escueto "ell no tenia vergonya." (1998: 32). El caso más claro és el de Auca tràgica i mort de Plem, donde el erotismo del texto original queda notablemente atenuado. La frase "A poc a poc, el Plem cesa en l'afany d'orgia, i els parpres se li van tancant i, finalment, s'adormia" (1998: 17) se convierte en "A poc a poc, s'adormia" (1998: 17), y "Era Plem, un fill del Plem! Engendrat en la barroeria de la cova" (1998: 22) es parafraseado eufemísticamente: "Un fill del Plem: a vegades les coses en aquell temps es complicaven." (1998: 22). Parece obvio que Espriu revisó su obra para eliminar aquellos aspectos controvertidos que podían comprometer su posición en el sistema literario catalán. El poco conocido Espriu de los años 30 era un narrador audaz muy diferente al poeta civil y patriótico al que estamos acostumbrados; el escritor de los años 40, en cambio, se dedicó a expurgar aquellos aspectos de su obra que podían haber incomodado los círculos resistentes de posguerra, profundamente religiosos, para no comprometer el nuevo sentido que estaba tomando.

El contraste de la primera posguerra con los años 20 y 30 es enorme: los círculos resistentes, que abrazaron con fervor el catolicismo ultraconservador de la época, a menudo se posicionaron contra aquellos que representaban la continuación de los valores desinhibidos de Sagarra, Soldevila, Jordana o Llor. No sobran ejemplos: Marià Manent se negó a escribir el prefacio de Poesia de Pere IV (1949) de Joan Oliver por considerar que algunas composiciones eran indecentes (Oliver 1988: 39); Josep Palau i Fabre fue marginado por atreverse a leer el poema "La sabata" en una sesión de poesía clandestina (2008: 157); la editorial Selecta rechazó reeditar Vida privada de Sagarra (Pla 2007: 400); las traducciones de obras clásicas de la Col·leció Bernat Metge eran autocensuradas (Fuster, 2010: 29); Baltasar Porcel, a quien le fue negado un premio en el certamen literario de Cantinogrós porque el text era demasiado osado, afirmó que "quieren que se escriba al dictado católico y democristiano" (Villalonga y Porcel 2011: 226); Miquel Llor publicó una continuación de Laura a la ciutat dels sants titulada El somriure dels sants (1947) para hacerse perdonar sus pecados, y Blai Bonet se convirtió en un apestado por atreverse a publicar El mar (1958).

Desafiando el ambiente pío y enrarecido de postguerra, en los años 40 Palau i Fabre escribe "poemes escabrosos i els llegeix als cenacles conservadors de la Barcelona vençuda" (Guillamon 2008: 16), lo que provocó el inmediato repudio de su entorno. La inclusión de poemas como "La sabata" y "Paradís atroç" en Cáncer (1946), publicado en Francia, agravó aún más la situación (Palau i Fabre 2008: 227). El libro, que "representaba el meu crit de rebel·lió i de confrontació máxima amb la societat barcelonina i amb l'estètica anquilosada" (2008: 165), circuló poco en Cataluña porque los miembros de la resistencia cultural se negaron a distribuirlo. El narrador de "La sabata", que obviamente se identificó con Palau, reconoce en el primer verso que se ha acostado con una prostituta; en la segunda estrofa, acusa a las mujeres de su entorno de no haber sabido satisfacer sus necesidades físicas y, en la última, avisa a parientes y amigas que ya no quiere más falsedades en su vida. En uno de los poemas que siguen, "Paradís atroç", la amante del narrador -que, efectivamente, se ha quitado la máscara- le pide sexo oral.

El somriure dels sants (1947), segunda parte de la novela más conocida de Llor, adquiere un sentido análogo al proceso de reescritura de Espriu. Llor tuvo como objetivo reconciliarse con Vic, y para tal propósito desnaturalizó a su heroína: la Laura de posguerra ya no es el personaje independiente y luchador que abandona a su marido, sino una mujer 
sumisa y arrepentida que regresa al hogar y aprende a estar callada. El enmudecimiento, por lo tanto, se presenta como la solución a todos los problemas que sufrió Laura en los liberales años 30. No por casualidad, la acción del texto transcurre durante la guerra civil y la inmediata posguerra, un contexto en que muchos adoptaron voluntariamente el silencio y la contrición como vía para purgar los supuestos errores del pasado.

El mar (1956) de Blai Bonet, que trata de la relación entre dos jóvenes tuberculosos en un sanatorio mallorquín, suscitó estupor e indignación a partes iguales y fue recibida con mucha hostilidad. Bonet "recibió recriminaciones de monjes de la Abadia de Montserat y gente bien pensante de Cataluña" (Roque 1997: 31), y la novela se consideró "una blasfèmia contra tot el que de més sagrat té Cataunya" (Alzamora 1998). Josep Maria de Sagarra, también víctima del ostracismo, salió en defensa de Bonet publicando un artículo contra "la aspaventera beatería" de aquellos que se habían sentido ofendidos (1958: 5). Joan Fuster, comentando el caso con Rafael Tasis, exculpa El mar, pero sus palabras muestran con claridad cuál había sido su recepción general: "convenia que haguessiu dit, com heu dit, que no és una novel·la pornogràfica. Sembla que en aquest país la gent no sap què és [la] pornografia." (2009: 192; 4 setiembre 1958). La siguiente novela de Bonet, Míster Evasió, no escandalizó tanto; no por falta de motivo, sino seguramente porque ya pocos se dignaron a leerla. En cualquier caso, fue recibida con múltiples comentarios homófobos: "Igual que en Míster Evasió, en el resto de tu obra hay también esa misma clase de vidas que mucha gente clasifica como 'depravación', 'mala vida'. ¿Cuál es tu intención, al preferir la descripción de estas vidas, a la descripción de vidas más saludables?” Bonet respondió que "En la zona humana de la vida, no hay que clasificar en alto y bajo, en normal y anormal, porque casi todas las formas de vida son buenas" (Mateu 1969).

Como hemos visto, durante las dos primeras décadas del siglo $\mathrm{XX}$ un grupo de intelectuales contestatarios intentó modernizar la cultura catalana, que aún se encontraba muy influenciada por los temas y estilo del siglo XIX. Igual que en otros países europeos, la necesidad de consolidar una nueva función para el escritor se reforzó con innumerables controversias que periódicamente zozobraron el campo literario. Los modernistes, los primeros en introducir una nueva concepción del arte y el intelectual que rompía los lazos entre estética y moralidad, no podían esperar más que rechazo y, como estrategia compensatoria, se dedicaron a subrayar su independencia e indiferencia hacia el público burgués. Su culto al arte por el arte era una ideología obviamente interesada que terminó dando sus frutos, ya que abrió el camino a la profesionalización del escritor y condujo a una nueva manera de concebir la obra artística.

La literatura de la primera mitad del siglo XX, catalista de debates sociales de gran alcance, era considerada por unos como un producto aleccionador cuya función era garantizar la continuidad y reproducción de la ideología dominante, mientras que para otros era un espacio privilegiado de resistencia y renovación. Los primeros consideraban que el arte era una herramienta de autocontrol y el artista debía ejercer un liderazgo moral; para los segundos, era un instrumento de autorealización y búsqueda de la propia identidad. El debate, por lo tanto, se desarrolló entre dos concepciones del arte: una perspectiva moralizante según la cual la piedad, la pureza y la harmonía espiritual enaltecían las virtudes de la obra, y una perspectiva estética no muy alejada del nihilismo que defendía una nueva idea de la belleza que no excluía la vulgaridad y el hedonismo. Se produjo, por lo tanto, una ruptura en las relaciones entre los presupuestos éticos y estéticos; como postuló Soldevila, el nuevo arte no era moral ni inmoral: era, simplemente, amoral. Si el anhelo creador del 
intelectual estaba por encima de todo, entonces ya no había prejuicios morales que valiesen: todo lo que quedaba plasmado en el texto, por obsceno o desagradable que pareciera, alcazaba la categoría de arte.

Ante la incomprensión del público burgués o los sectores católicos más fervorosos, los nuevos intelectuales convirtieron el rechazo en vara de medir de su éxito. Pocos agentes sociales necesitan tanta visibilidad como los escritores, y la ruptura con la moral imperante en favor de una estética pura les permitió labrarse una imagen pública de gran impacto. No era una imagen, claro está, positiva, pero sirvió perfectamente a sus intereses, puesto que la literatura y las obras literarias se nutren y crecen con los ataques que sufren: no hay nada más atractivo para el lector que un libro vilipendiado, censurado o prohibido. Las críticas infamantes llaman la atención sobre la obra, señalando que no es un producto convencional, y nada hay más carente de interés en la república de las letras que el formulismo. Para estimar la capacidad de un libro de entrar en el canon, por lo tanto, hay que medir el calibre de las críticas que recibió; cuanto más tinta se vertió para desacreditarlo, más posibilidades existen de que sobreviviera el contexto en que fue creado. Dos factores clave lo prueban: en primer lugar, todas las obras que se han examinado merecieron comentarios elogiosos y fueron bien recibidas por parte del público, pero lo que las transformó en piedra angular de la producción literaria de su tiempo fue su capacidad de escandalizar; en segundo lugar, las obras vituperadas se encuentran entre las que hoy en día consideramos las mejores del periodo, mientras que la mayor parte de las que consiguieron un respaldo unánime cayeron rápidamente en el olvido. En sociedades abiertas, por lo tanto, la publicidad negativa es sumamente importante, ya que pone la obra en el mapa y crea un clima de interés que con frecuencia sobrevive al autor.

En los años cuarenta, a causa de la dramática alteración de la dinámica sociocultural, el contexto ya no favorecía el escándalo, que se convirtió en un factor mucho más dañino para la reputación del escritor. Un buen ejemplo de ello es el caso de Sagarra, que en los 30 había jugado muy bien con los resortes de la polémica, actitud que en la oscura posguerra no fue perdonada y lo condenó al aislamiento. Asimismo, Bonet tampoco buscaba la confrontación, inevitable en la atmósfera intransigente y hostil de posguerra para quien se desviara un poco de los valores imperantes. Esto explica el silencio respecto a las características de la obra espriuana de preguerra y, también, la marginación de Palau i Fabre en el canon.

Para concluir, soy consciente de que algunas de las ideas desarrolladas en este artículo, particularmente las que se refieren al campo cultural de posguerra, pueden levantar ampollas. En todo caso, no es baladí recordar que el mundo académico no es sino un subconjunto del sistema literario y que, por lo tanto, en lo que se refiere a la polémica rigen las mismas reglas. Se ha afirmado al principio que un campo literario sin controversia ha dejado de funcionar como tal: el noucentisme, por ejemplo, emprendió conscientemente este camino y, aunque pocos lo hayan reconocido abiertamente (véase Santaeulàlia 1999: 120-126), el experimento fracasó y a finales de los años 20 tuvo que reconducirse la situación. Exactamente lo mismo puede decirse del discurso académico: si se limita a repetir ideas y esquemas ya conocidos sin intentar cuestionarlos o analizarlos desde nuevos puntos de vista, se corre el riesgo de fosilizar la materia de estudio y, como máximo, suscitar indiferencia. Era por lo tanto inevitable -y consecuente con el tema tratado- que un estudio dedicado al escándalo en la literatura terminase siendo controvertido; esta era la mejor manera posible de rendir tributo a unas obras que fueron muy rompedoras en su contexto. Si Sagarra, Jordana, Albert, Palau i Fabre, Bertrana, Bonet o Llor causaron -buscándolo o no- 
indignación, el homenaje más justo y sincero solo puede consistir en seguir el mismo rumbo que tomaron e interpretar su obra desde una perspectiva igualmente controvertida para que siga manteniéndose tan original y provocadora como cuando se publicó.

\section{Bibiografia}

A.F., (1930): "Una novel·la pornográfica, per favor!". Mirador 5 (16 enero): 4.

Alzamora, S. (1998): “Blai Bonet, delicada agressió". Serra d'Or 457: 48-53.

ANGELAS, F. (1993): L'amor i l'erotisme en la literatura catalana. Barcelona, Barcanova.

ARNAU, C. (1987): Marginats i integrats en la novel la catalana, 1925-1938. Introducció a la novel·lística de Llor, Arbó, Soldevila i Trabal. Barcelona, Edicions 62.

BARTrina, F. (2001): Caterina Albert/Víctor Català: la voluptuositat de l'escriptura. Vic, Eumo.

BARTRINA, F. (1997): "Teatre de dona al tombant del segle: La infanticida de Caterina Albert". Lectora: revista de dones $i$ textualitat 3: 40-48.

Bertrana, P. (1910): “Remitido". Diario de Gerona (16 junio): 10-12.

Bourdieu, P. (1996): The Rules of Art, trad. Susan Emanuel. Stanford, Polity Press.

CALDERER, L. (1995): De la veu a la lletra. Barcelona, Columna.

CAMPILlo, M. (1977): "Situació i sentit d'Una mena d'amor de C. A. Jordana”. Els Marges, 11: 101-109.

CAPDEVILA, J.M. (1929): “Fanny”. El Matí, 31 diciembre.

CAsacuberta, M. (1995): "Gènesi i primera adjudicació del Premi Crexells. Notes sobre cultura i novel·la en el tombant dels anys vint als trenta". Els Marges 52: 19-42.

CASACUberta, M. (1997): Santiago Rusiñol: vida, literatura i mite. Barcelona, Curial.

CASACUBerTA, M. (2010): "Modernisme: gèneres i autors", en Panorama crític de la literatura catalana, V. Segle XX: Del Modernisme a l'Avantguarda. Barcelona, Vicens Vives, pp. 76-104.

CASTEllanOS, J. (1982): "El districte cinquè i la novel-la catalana dels anys trenta". Els Marges 26: 115-119.

Castellanos, J. (1989): “Narrativa i erotisme, 1862-1936”. L'Avenç 123: 28-33.

Castellanos, J. (1992): Raimon Casellas i el Modernisme, 2 vol. Barcelona, Curial.

CAstellanos, J. (2001): “Josafat, novel·la modernista”, en P. Bertrana, Josafat. Barcelona, Edicions 62, pp. 1-39.

Cornellà-Detrell, J. (2011): Literature as a Response to Cultural and Political Repression in Franco's Catalonia. Woodbridge, Tamesis, pp. 62-87.

CORNELLÀ-DETRELL, J. (2012): "Quan el metge és la malaltia: higiene, neurastènia i sífilis a la 'trilogia femenina' de Carles Soldevila". Journal of Iberian and Latin American Studies 18 (2-3): 129-143.

Costa i Torró, M. C. (2010): “All i salobre”. Diari de Girona (11 enero): 2.

Dromi, S. y E. Illouz (2010): "Recovering Morality: Pragmatic Sociology and Literary Studies". New Literary History 41.2: 351-369.

ESClASANS, A. (1925): “L'editor fantàstic”. La Revista (junio): 167.

ESPRIU, A. (1996): Salvador Espriu. Barcelona, Columna.

EsPrIU, S. (1998): Aspectes, ed. G. Gavagnin y V. Martinez-Gil, Barcelona, Edicions 62.

FARRÉS, P. (1994): Josafat, de Prudenci Bertrana. Barcelona, Empúries.

Fuster, J. (2009): Correspondència 11: Rafael Tasis, Joan Triadú, Antoni Comas, Albert Manent i Joaquim Molas, ed. Josep-Vicent Garcia i Raffi. Valencia, Edicions $3 i 4$. 
Fuster, J. (2010): Correspondència 12: Rafael Tasis, Joan Triadú, Antoni Comas, Albert Manent i Joaquim Molas, ed. Josep-Vicent Garcia i Raffi. Valencia, Edicions $3 \mathrm{i} 4$.

GAdEA Y GAMBÚs, F. (1994): Lectures de COU 1994-95. Barcelona, La Magrana, pp. 77112.

Granell i Nogué, G. (2002): “Josafat de Prudenci Bertrana. Polèmica a la festa de la bellesa de Palafrugell (1905) i recepció psoterior de l'obra". Annals de l'Institut d'Estudis Gironins 43: 245-261.

Granell i Nogue, G. (2003): Prudenci Bertrana: els primers passos de l'artista. Girona, Ajuntament de Girona.

Granell i NoguÉ, G. (2006): Bertrana i Varés: la Girona de Josafat. Girona, Ajuntament de Girona.

GRAU, F. (1995): "Introducció", en C.A. Jordana, Una mena d'amor. Barcelona, Columna.

GUANSÉ, D. (1931): “Un llibre per a la joventut”. La Rambla 47 (16 noviembre): 4.

GUANSÉ, D. (1932): "Els llibres nous. Vida privada de Josep M. de Sagarra". La Publicitat (3 noviembre).

GuIllamon, J. (2008): “El monstre: biografia impura”, en J. Palau i Fabre, El Monstre $i$ altres escrits autobiogràfics, ed. J. Guillamon. Barcelona, Cercle de Lectors.

GustÀ, M. (1981): "Notes sobre Vida privada". Els Marges 22/23: 33-48.

Howells, R., A.D. RitivoI y J. Schachter (2012): "Introduction", en Outrage: Art, Controversy, and Society, ed. R. Howells, A.D. Ritivoi, J. Schachter. Houndmills, Palgrave Macmillan, pp. 1-16.

Howells, R. (2012): “Controversy, Art, and Power", en Outrage: Art, Controversy, and Society, ed. R. Howells, A.D. Ritivoi, J. Schachter. Houndmills, Palgrave Macmillan, pp. $19-46$.

IRIBARREN, T. (2011): "La recepció de Lawrence a la Barcelona de Preguerra". Journal of Catalan Studies: 110-128.

JACOBSSON, K. y E. LÖFMARCK (2008): “A Sociology of Scandal and Moral Transgression”. Acta Sociologica 51.3: 203-216.

JordANA, C.A. (1995): Una mena d'amor. Barcelona, Columna.

LlateS, R. (1929): "Pornografia servida en blanques". Mirador 16 (16 mayo): 4.

MARFANY, J.L. (1975): Aspectes del modernisme. Barcelona, Curial.

Mateu, M. (1969): “Míster Evasió, Blai Bonet, 1969”. Diario de Mallorca (25 mayo), http://www.mallorcaweb.com/magpoesia/bonet-blai/paraula.htm [2 Mayo 2014].

Montoliu, M. de (1926-1933): Breviari crític, IV vol. Barcelona, Biblioteca Balmes.

Montoliu, M. de (1928): La Veu de Catalunya (26 agosto).

Montoliu, M. de (1933): "Carles Soldevila, Fanny", en Breviari crític, IV. Barcelona, Biblioteca Balmes, pp. 258-262.

Montoliu, M. (1933): "Breviari crític. Josep M. de Sagarra, Vida privada". La Veu de Catalunya (15 febrero): p. 7.

NADAL, M. (1995): “Josafat de Prudenci Bertrana”, Lectures de COU 1994-1995. Barcelona, La Magrana, pp. 7-23.

OlCINA, E. (2012): "La por i el fàstic. Josafat i el gòtic modernista", en Llibres, monstres $i$ catedrals: Josafat de Prudenci Bertrana, ed. X. Pla. Girona, Universitat de Girona, pp. 49-61.

Oliver, J. y J. Ferrater Mora (1988): Joc de cartes 1948-1984, ed. Antoni Turull. Barcelona, Edicions 62. 
D’Ors, E. (2005 [1913]): “Un Amiel vigatà”, Glosari 1912-1913-1914, ed. X. Pla. Barcelona, Quaderns Crema, pp. 543-554.

PAlau i Fabre, J. (2008): El Monstre i altres escrits autobiogràfics, ed. J. Guillamon. Barcelona, Cercle de Lectors.

Panyella, V. (2010): "El Noucentisme", en Panorama crític de la literatura catalana, $V$. Segle XX: Del Modernisme a l'Avantguarda. Barcelona, Vicens Vives, pp. 270-295.

PERMANYER, L. (1982): Sagarra, vist pels seus intims. Barcelona, Edhasa.

PlA, X. (2007): "Recepció i contradicció en les edicions de Vida privada", en J. M. de Sagarra, Vida privada. Barcelona, Proa, pp. 387-409.

PLA, X. (2010a): "Nous valors: canvi estètic als anys vint i trenta", en Panorama crític de la literatura catalana, V. Segle XX: Del Modernisme a l'Avantguarda. Barcelona, Vicens Vives, pp. 384-429.

Pla, X. (2010b): "Josep M. de Sagarra”, en Panorama crític de la literatura catalana, . Segle XX: Del Modernisme a l'Avantguarda. Barcelona, Vicens Vives, pp. 598-614.

PLA, X. (2012): "Els orígens de Josafat. Breus reflexions a l'entorn d'un manuscrit inèdit de Prudenci Bertrana", en Llibres, monstres i catedrals: Josafat de Prudenci Bertrana, ed. X. Pla. Girona, Universitat de Girona, pp. 101-124.

PRUS, R. y Grills, S. (2003): The Deviant Mystique: Involvements, Realities and Regulation. Westport, Greenwood Press.

PUIG I FERRATER, J. (2001 [1904]): "La dama alegre", Teatre complet, 2. Tarragona, Arola Editors, pp. 9-88.

REAL, N. (2006): Dona i literatura a la Catalunya de preguerra. Barcelona, Publicacions de l'Abadia de Montserrat.

RodoredA, M. (1933): "Una estona de conversa amb Miquel Llor". Clarisme 8 (9 diciembre): 2.

RoQue, J.M. (1997): "Fallece a los 71 años el escritor Blai Bonet”. La Vanguardia (22 diciembre): 31.

Rose, N. (1998): "Medicine, History and the Present", en Reassessing Foucault: Power, Medicine and the Body, ed. C. Jones i R. Porter. Londres, Routledge, pp. 48-71.

SAntAeulÀlia, J. N. (1999): "Noucentisme i literatura", en Literatura catalana contemporània, ed. Glòria Bordons y Jaume Subirana. Barcelona, Proa, pp. 120-126.

SAGARRA, J. M. de (1929): All i salobre. Barcelona, Llibreria Catalònia.

SAGARRA, J. M. de (1958): "El señorío de Mallorca". La Vanguardia (29 junio): 5.

SoldEVILA, C. (1930): “Quatre paraules preliminars", en Fanny, 2a ed. Barcelona, Llibreria Catalònia.

TASIS, R. (1937): La literatura catalana moderna. Barcelona, Comissariat de Propaganda de la Generalitat de Catalunya.

VilamitjanA, J. (2009): "No és pas tan lluny”. Diari de Girona (11 diciembre): 26.

VillalongA, L. y B. PORCEL (2011): Les passions ocultes. Correspondència i vida. Epistolari complet (1957-1976). Barcelona, Edicions 62.

YATES, A. (1975): Una generació sense novel-la?: La novel-la catalana entre 1900 i 1925. Barcelona, Edicions 62. 